\title{
In pursuit of the shiftworker: A discussion of methodologies
}

\author{
WILSE B. WEBB \\ University of Florida, Gainesville, Florida 32611
}

Methodologies used in the study of shiftwork are discussed.

As noted in the introductory remarks, shiftwork, or the scheduling of work outside of the "standard" work period of (approximately) 8:00 a.m. to 5:00 p.m., is becoming pandemic in industrial society. While, as Shakespeare noted, it has always been the case that "some must watch while some must sleep" (Hamlet, Act III, Scene 2), the present extent of this variation is a modem phenomenon. I believe that sleep was laid down and deeply embedded as a biological system that set work periods in the day and sleep periods during the night in a fixed pattern. Minimally, the sleep research data force the conclusion that sleep has the substantial characteristics of a biological rhythm. This implies a tendency for the systematic recurrences of sleep (and work) to be potentiated in a relatively fixed time schedule. Shiftwork works against these assumptions.

Without judging the extent of the effects, this massive and modern behavioral event deserves a serious effort. From my point of view, it needs an intensive analysis. Although it is clear that people can endure shiftwork (it seems one of the few things yet unlinked with cancer), I view it as another contribution of modern society to mankind's further impoverishment. Simply, shiftwork is a fine example of the contemporary stance that appears to be that nature must accede to man rather than man being in accord with nature.

The preceding set of papers described some intrepid forays into shiftwork research with a focus on the methodological aspects. They echo and rebound with the familiar problems associated with the study of behavioral and biological events embedded in the real world of day-to-day living.

Certainly, one must admire these efforts as one admires searches in the past for the causes and effects of an endemic problem in a large population. We properly applaud the earlier efforts of the malaria and typhoid hunters of the past and the swarming search for cancer-bearing elements of the present.

But admiration here must be mixed with sympathy. The symptoms of shiftwork are not neat temperature or abnormal growth signals, nor are the causes directly organismic. The symptoms range from detailed and discrete physiological changes to subtle psychological states of malaise and errors. The causes are comprised of a mixture of variables involving crying babies, marital quarrels, transportation distances, wage differentials, and biological rhythms. Certainly, sympathy must be extended to the shiftwork researcher, who must pursue an effect that is seldom deadly and disastrous but of ten a dreariness that is unpleasantly tolerable, or who must grapple with causes that are parts of a noisy social fabric and are loosely de termined by lawfulness.

The papers presented here are excellent examples of the trials and successes involved in this area of research. Colligan, Smith, Hurrell, and Tasto review the approach and problems of utilizing retrospective records as measures. Smith and his colleagues present aspects of a questionnaire methodology in this area. The paper by Gordon, Tepas, Stock, and Walsh focuses on the particularized application of a survey approach, and Walsh, Gordon, Maltese, McGill, and Tepas discuss the use of laboratory measurements as they have been interfaced with worker survey and field interview procedures.

I have reviewed these papers with great interest and profit. I have, for some years, been engaged in laboratory studies of the effects of shiftwork on sleep (Webb, Agnew, \& Williams, 1971). More recently, in recognition of the limits of such studies, we completed a "quasi-field study" in which subjects, while housed in the laboratory and thus socially "sanitized," were given self-choices of sleep (Webb \& Agnew, 1978). This was an attempt to have the best of the two worlds: reality and laboratory control.

The area of shiftwork and this group of papers emphasize that in study of behaviors, which may be identified and must be understood in an environmental context, there is the necessity to neglect neither the field study nor the laboratory study. But this is not easy. Some elements of the problem of relating "real-life" data and laboratory data were noted in a symposium on sleep and performance (Webb, 1977, p. 101):

"Some of us, by necessity or the opportunities of our work environments or choices stemming from our training or inclinations, will pursue the applied aspects of our field. As such, we will emphasize the utilitarian, realistic, coherent, applicable, and 'person-centered' nature of our findings. Others will find satisfaction in laboratory experiments and in the controlled, quantifi- 
able, testable, and 'principle-centered' aspects of our research.

"Too often this results in an emphasis on the good aspects of our own chosen approach and depreciation or ignoring of the other. This may result in sneers about the 'sloppiness' of the applied worker or the 'silly games' of the experimentalist. This, of course, helps neither our image with others nor improves our efforts.

'In fact, these are more often arguments about ends and means; the ends toward which our data should be directed and the means to achieve these ends. And we know, on reflection, that good means do not justify bad ends nor bad means are not justified by good ends. The best researchers, when considering real life problems, make every effort to incorporate the valued methods of laboratory research; explicitly defined terms, controlled and repeated obsservations, quantification and a search for general principles. The best of the laboratory workers approaches his research with a conscious concern about the meaningfulness, coherence, and ultimate life-centered applicability of his results."

I would conclude with my belief that the present papers show a healthy concern with the best elements of field and laboratory approaches.

\section{REFERENCES}

WeBB, W. B. Sleep and performance. In W. P. Koella \& P. Levin (Eds.), Sleep 1976. Basel: Karger, 1977.

WEBB, W. B., \& AGNEW, H. W., JR. Effects of rapidly rotating shifts on sleep patterns and sleep structure. Aviation, Space and Environmental Medicine, February 1978, 384-389.

Webb, W. B., Agnes, H. W., JR., \& Williams, R. L. Effect on sleep of a sleep period time displacement. Aerospace Medicine, 1971, 42, 152-155. 